\title{
A Practical and Economical Route to (S)-Glycidyl Pivalate
}

\author{
Jeffrey M. Noble, ${ }^{\mathrm{a}}$ Le Chang, ${ }^{\mathrm{b}}$ Dan Chen, ${ }^{\mathrm{b}}$ Binglin Wang, ${ }^{\mathrm{b}}$ Raymond N. Dominey, ${ }^{\mathrm{c}}$ Daniel W. \\ Cook, ${ }^{a}$ Justina M. Burns, ${ }^{a}$ Rodger W. Stringham, ${ }^{a}$ Flavio S. P. Cardoso,,${ }^{a}$ and David R. Snead ${ }^{* a}$
}

\section{AUTHOR ADDRESS}

a) Medicines for All Institute, 737 N. 5th St., Box 980100, Richmond VA, 23298-0100

b) WuXi AppTec (Wuhan) Co. Ltd., Wuhan East Lake High-tech Development Zone, Wuhan 430075, P. R. of China

c) Department of Chemistry, Gottwald Center for the Sciences, University of Richmond, VA 23173

\begin{abstract}
An efficient method to prepare enantiopure $(S)$-glycidyl pivalate from $(R)$-epichlorohydrin and pivalic acid is reported. This work provides an alternative to the synthesis of this important building block from readily available and inexpensive materials.
\end{abstract}

Keywords: Tuberculosis $•$ API $・$ Pretomanid $\bullet$ Epichlorohydrin $\bullet$ Supply centered synthesis

\section{Introduction}

Tuberculosis is one of the leading global causes of mortality, and it is believed that one third of the population has a latent case of the disease. ${ }^{1}$ Pretomanid is a therapy for treatment of tuberculosis, and was recently approved by the US FDA under the Limited Population Pathway (LPAD Pathway) for treatment of pulmonary extensively drug resistant (XDR) tuberculosis in combination with bedaquiline and linezolid. It works as a respiratory poison against bacteria by releasing nitric oxide under anaerobic conditions.

Given the large quantities of drug substance that could be required, cost-effective syntheses are needed. A key feature of pretomanid is the dihydro-1,3-oxazine, containing an oxygen-substituted asymmetric center on the $\mathrm{C}_{3}$ unit (Figure $1)$. One could foresee installation of this fragment from an (S)-glycidol derivative, and not surprisingly many of the current pretomanid routes make use of functionalized glycidols. $^{2}$

Glycidyl pivalate appears to be a particularly important variant. ${ }^{3}$ Enantiomers of optically active glycidol are of considerable expense, however, construction from less expensive precursors would be desirable. Epichlorohydrin is a feedstock chemical, and its pure enantiomers are highly available in comparison to those of glycidol. As a result, $(R)$-epichlorohydrin is approximately 5-6\% of the $\operatorname{cost}^{4}$ of
$(S)$-glycidol and could thus form the basis for a more costeffective route to this intermediate.

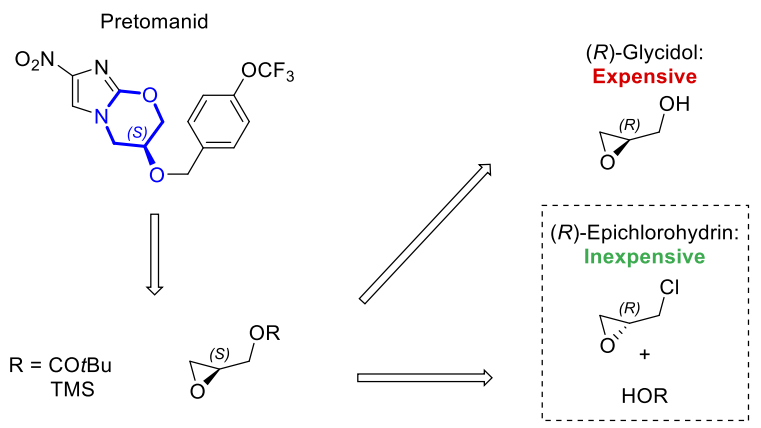

Figure 1: Pretomanid retrosynthesis from protected glycidols.

Numerous reports describe reaction of epichlorohydrin with carboxylates, particularly hindered carboxylates, as the ensuing glycidyl esters are used in alkyd resins, paints, coatings, and acrylate monomer compositions. ${ }^{5}$ Fewer reports detail the reaction of enantiopure epichlorohydrin with carboxylic acid derivatives. ${ }^{5 i-k}$ This work describes development of a practical route to $(S)$-glycidyl pivalate from low-cost and readily available $(R)$-epichlorohydrin and pivalic acid. 


\section{Results and Discussion}

Our investigation began with a screen of typical conditions used to couple acids with racemic epichlorohydrin (Table 1). Equivalents of starting material, preformation of the carboxylate, solvent, temperature and time were explored. In our hands, introducing an excess of epichlorohydrin was advantageous (Entries 4-6). Furthermore, removal of exogeneous solvent led to the best results, giving glycidyl ester 3 in greater than $95 \%$ assay yield (AY). While a high stoichiometry of epichlorohydrin was employed, we were encouraged that these conditions could be rendered economical if excess starting material were to be recovered.

Table 1: An initial screen of conditions for glycidyl pivalate synthesis using racemic epichlorohydrin.

\begin{tabular}{|c|c|c|c|c|c|c|c|}
\hline \multirow{3}{*}{$>_{1}^{\mathrm{O}}$} & \multirow{3}{*}{$\begin{array}{c}H^{+} \\
\text {Epi. } \\
\text { (Equiv.) }\end{array}$} & \multirow{2}{*}{\multicolumn{2}{|c|}{${ }_{2}^{\circ}$}} & \multicolumn{2}{|c|}{ Base } & \\
\hline & & & & & & & \\
\hline & & (Equiv.) & $\left({ }^{\circ} \mathrm{C}\right)$ & (hr) & Solvent & (LCAP) & Ref. \\
\hline 1 & 0.6 & $\begin{array}{l}\mathrm{NaOH} \\
(0.25)\end{array}$ & 55 & 2 & $\underset{(1: 1)}{\mathrm{EtOH} / \mathrm{H}_{2} \mathrm{O}}$ & ND & [6] \\
\hline $2^{\mathrm{a}}$ & 0.9 & $\begin{array}{l}\mathrm{NaOH} \\
\text { (1) }\end{array}$ & 110 & 12 & Toluene & ND & {$[5 c]$} \\
\hline $3^{b}$ & 1.08 & $\begin{array}{c}\mathrm{NaOH} \\
(1.5)\end{array}$ & 70 & $1-25$ & - & ND & {$[4 \mathrm{~h}]$} \\
\hline $4^{a}$ & 2 & $\begin{array}{c}\mathrm{K}_{2} \mathrm{CO}_{3} \\
(2)\end{array}$ & 80 & 12 & $\mathrm{MeCN}$ & $9 \%^{d}$ & [7] \\
\hline 5 & 5 & $\begin{array}{c}\mathrm{K}_{2} \mathrm{CO}_{3} \\
(0.02)\end{array}$ & 90 & 2 & $\mathrm{H}_{2} \mathrm{O}$ & $\mathrm{ND}$ & [8] \\
\hline $6^{c}$ & 10 & $\begin{array}{c}\mathrm{NaOH} \\
\text { (1) }\end{array}$ & 120 & 2 & - & $96 \%$ & [4d] \\
\hline
\end{tabular}

a) $20 \mathrm{~mol} \%$ tetrabutylammonium bromide (TBAB). ${ }^{\text {b) }} 8 \mathrm{~mol} \%$ tetramethylammonium chloride (TMAC, $50 \%$ aq.). ${ }^{c)} 1.5 \mathrm{~mol} \%$ tetramethylammonium chloride. d) \% Yield determined by qNMR using 1,3,5-trimethoxybenzene as internal standard.

We subsequently shifted our focus on isolation of the desired compound from the reaction mixture, and the reaction scale was increased to $20 \mathrm{~g}$ of pivalic acid and $182 \mathrm{~g}$ (10 Eq.) of $(S)$-epichlorohydrin (Scheme 1). We expected that the high assay yield and simplicity of chemical inputs would facilitate isolation. The reaction of sodium pivalate with epichlorohydrin produced one equivalent of sodium chloride which was easily removed via filtration as a result of its low solubility. Next, the epichlorohydrin (bp $118{ }^{\circ} \mathrm{C}$ ) was evaporated and collected. A high proportion of the theoretical amount was collected, an important consideration in rendering an economically viable synthesis (143 g, 87\%). The residual crude glycidyl pivalate $(33 \mathrm{~g}, 6 \%$ epichlorohydrin) was distilled twice at $50-70{ }^{\circ} \mathrm{C}$ under high vacuum ( 6-10 Torr), resulting in 74\% isolated yield of the pure glycidyl pivalate. The compound appeared to be temperature sensitive at high concentration, and thus heat history was minimized. The product showed high optical activity $\left(-21.87, \mathrm{CHCl}_{3}, 25^{\circ} \mathrm{C}\right)$ as compared to literature values for $(S)$-glycidyl pivalate (20.7); however, the sign of rotation was inverted indicating that the undesired $(R)$ enantiomer had been made. Starting from $(R)$ - epichlorohydrin led to $(S)$-glycidyl pivalate samples with $[\alpha]_{D}$ values of $18.8^{\circ}$ and $18.9^{\circ}$. Attack of the pivalate anion on the epoxide rather than the primary chloride rationalizes this observation. Despite these highly encouraging results, analysis of the recovered epichlorohydrin revealed that the epoxide racemized over the course of the reaction.

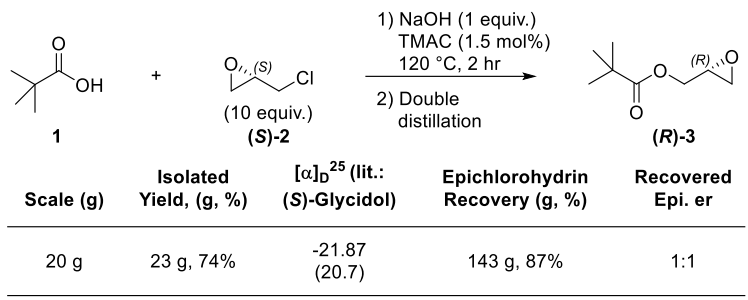

Scheme 1: $20 \mathrm{~g}$ scale-up transposed from initial conditions with isolation of optically pure glycidol pivalate.

Further reaction screening was required to identify a costeffective system. Our approach was that either epichlorohydrin epimerization would need to be fully suppressed or that consumption of epichlorohydrin would need to be decreased in order to negate the requirement of starting material recycle. We first explored suppression of epimerization with the thought that at lower temperatures, the rate of substrate racemization might be significantly slower. The esterification was run at $60{ }^{\circ} \mathrm{C}$ in high assay yield. At this temperature, the enantiomeric ratio increased from 50:50 to 90:10 (Table 2, Entries 1-2). While this was a positive development, further improvements were required. The high assay yield was maintained at $50{ }^{\circ} \mathrm{C}$, and enantiomeric ratio was elevated to $95: 5$ (Entry 3). This moved the conditions toward economic viability, however, even slight erosion of optical activity limits the ability to recycle epichlorohydrin.

Removing the need for the epichlorohydrin recycle would be preferable as it would simplify the system. If the epichlorohydrin excess could be reduced, the economic driver for recycle of the starting material would be eliminated. However, simply reducing the equivalents of epichlorohydrin led to much lower yields, and a large amount of decomposition was observed (Entries 4-5). The root cause was believed to be a heat sensitivity, where bimolecular degradation of the product most likely accelerated at elevated concentrations. To evaluate this hypothesis, the reaction run with 3 or 6 equivalents of epichlorohydrin was simply diluted with inert chlorobenzene to a volume equivalent to that of 10 equivalents of epichlorohydrin. This did indeed provide a significant increase to yield at and above $80 \%$ (Entries 6-7). Decreasing temperature to $60{ }^{\circ} \mathrm{C}$ was found to be the best solution as it further increases yield, avoids the need for exogenous solvent, greatly increases throughput of material, and renders the system highly economical as compared to glycidol. 
Table 2: Optimization for the synthesis of glycidol pivalate.

\begin{tabular}{|c|c|c|c|c|c|}
\hline \multirow[b]{2}{*}{ Entry } & \multirow{2}{*}{$\begin{array}{c}+ \\
\text { Epi. } \\
\text { (Equiv.) }\end{array}$} & \multirow{2}{*}{$\begin{array}{l}{ }_{2} \mathrm{Cl} \\
\text { Temp. } \\
\left({ }^{\circ} \mathrm{C}\right)\end{array}$} & \multicolumn{2}{|c|}{$\underset{\operatorname{TMAC}(1.5 \mathrm{~mol} \%)}{\mathrm{NaOH}(1.0 \text { equiv. })}$} & \multirow{2}{*}{ Epichlorohydrin } \\
\hline & & & $\begin{array}{c}\text { Time } \\
(\mathbf{h r})\end{array}$ & AY & \\
\hline 1 & 10 & 120 & 3 & $96 \%$ & $50: 50$ \\
\hline 2 & 10 & 60 & 3 & $98 \%$ & $90: 10$ \\
\hline 3 & 10 & 50 & 17 & $96 \%$ & 95:5 \\
\hline 4 & 6 & 120 & 3 & $62 \%$ & - \\
\hline 5 & 3 & 120 & 3 & $13 \%$ & - \\
\hline $6^{\mathrm{b}}$ & 6 & 120 & 3 & $88 \%$ & - \\
\hline $7^{b}$ & 3 & 120 & 3 & $80 \%$ & - \\
\hline 8 & 6 & 60 & 3 & $76 \%$ & - \\
\hline 9 & 6 & 60 & 24 & $98 \%$ & - \\
\hline 10 & 3 & 60 & 3 & $61 \%$ & - \\
\hline 11 & 3 & 60 & 24 & $93 \%$ & - \\
\hline
\end{tabular}

With the revised synthetic methods now in hand, we then sought Glycidyl pivalate isolation methods. Two solutions struck us as feasible:

1. Prepare an in situ solution of glycidyl pivalate

2. Access a higher purity variant via distillation

Each solution has benefits and drawbacks. The first option is desirable in that it avoids the distillation of the epoxide. Some temperature sensitivity was noted for the epoxide, and production of a reactive solution could maximize yield by limiting the heat history and concentration of the epoxide. However, this alternative does not provide a means of purifying the glycidyl pivalate, and the excess epichlorohydrin must still be removed. If successful, the second option provides a means of removing byproducts from the glycidyl pivalate to obtain a more highly controlled and pure product.

Production of an in situ solution was explored first (Figure 2). A solvent swap to toluene was desired as toluene could be used in the ensuing synthetic chemistry. In first attempts toward this goal, epichlorohydrin was directly distilled from the reaction mixture under vacuum, and then toluene was added intermittently to make-up the volume lost from epichlorohydrin evaporation. Volatiles were then fully removed to give a glycidyl pivalate residue. The process was repeated three times. This led to a loss of active glycidyl pivalate in solution as observed by decrease in the assay strength (10-15\%) and also the observation of unidentified by-products (Figure 2).

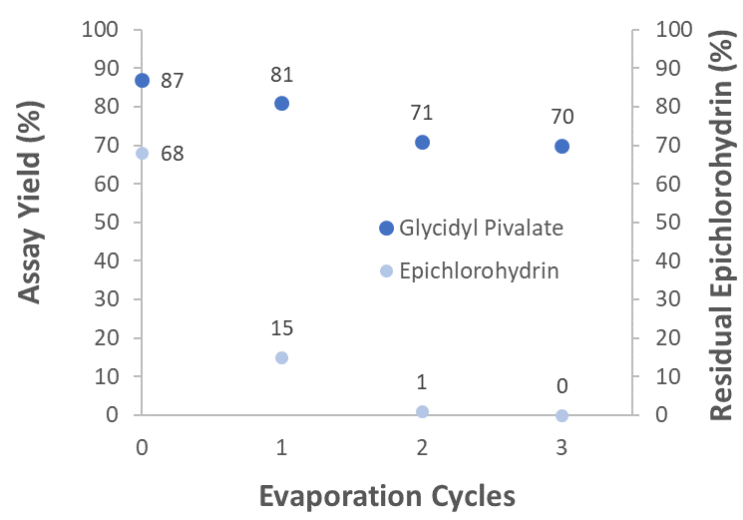

Figure 2: Impact of concentration on assay yield of glycidyl pivalate in toluene.

Again, heat and concentration sensitivities were suspected to cause the loss in activity. If the solvent swap could be conducted while maintaining constant volume, perhaps the decomposition could be avoided. This was accomplished by adding toluene continuously to a stirred solution of the glycidyl pivalate reaction mixture which was under vacuum (Figure 3). Performing the solvent swap in this manner largely prevented the loss of active glycidyl pivalate to decomposition products. The reaction mixture had a $94 \%$ $\mathrm{AY}$ at the end of reaction (EOR) and a 90\% AY after removal of epichlorohydrin through a toluene solvent swap. This yields a reactive solution which could be used for the subsequent alkylation step. ${ }^{2 \mathrm{~b}}$

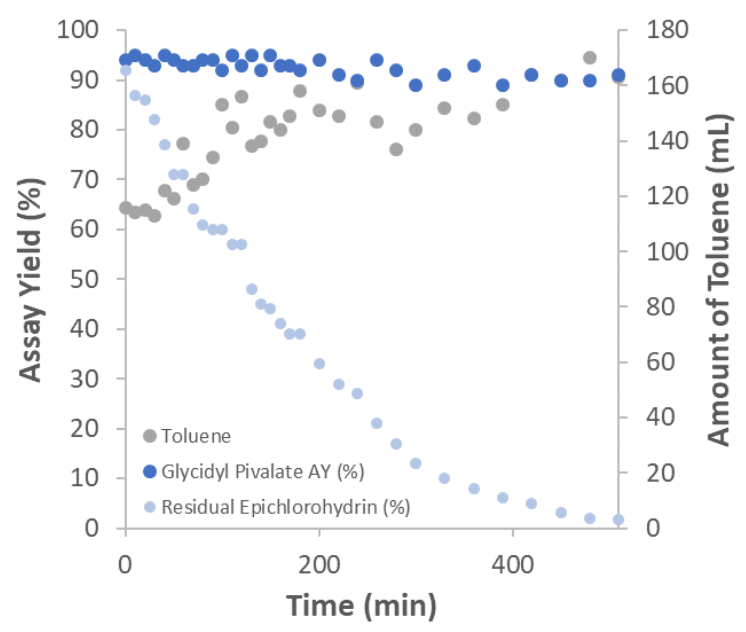

Figure 3: Solvent swap of epichlorohydrin for toluene with continuous addition of toluene to maintain constant volume.

Next, we attempted to isolate glycidyl pivalate in good purity by direct distillation ${ }^{9}$ (Table 3 ). First, sodium chloride was removed from the reaction mixture via filtration, and then epichlorohydrin was evaporated from the filtrate. Care was taken to evaporate epichlorohydrin at minimal temperature under strong vacuum $(<10$ torr $)$ so that vapors of epichlorohydrin do not exceed $60{ }^{\circ} \mathrm{C}$. After evaporation, the assay yield of the crude glycidyl pivalate residue was $87 \%$. 
The product was then distilled. Again, it was important to apply maximum levels of pressure so that the temperature of glycidyl pivalate did not exceed $70{ }^{\circ} \mathrm{C}$. At higher temperature, lower yields were observed as a result of product decomposition. Conditions used in this work were to distill at $50{ }^{\circ} \mathrm{C}$ and 6 Torr. The distillation was also scaledependent and yield increased significantly as glycidyl pivalate volumes grew. This is likely a function of system configuration which can be further optimized upon implementation, and might benefit from a continuous distillation system such as a thin-film evaporator so as to minimize thermal history of the heat sensitive compound. Isolated yield reached $76 \%$ with material of $95 \mathrm{wt} \%$ purity.

Table 3: Scale-up for the synthesis of glycidol pivalate.

\begin{tabular}{|c|c|c|c|c|c|c|}
\hline \multirow{2}{*}{$\overbrace{1}^{O} \mathrm{OH}$} & + & & \multicolumn{2}{|c|}{ 1) $\mathrm{NaOH}$ (1.0 equiv.) } & \multirow[b]{3}{*}{$\begin{array}{l}\text { Assay } \\
(w t \%)\end{array}$} & \\
\hline & & & 2) Dis & & & \\
\hline Entry & $\begin{array}{c}\text { Scale } \\
\text { (g) }\end{array}$ & $\begin{array}{l}\text { AY, } \\
\text { EOR }\end{array}$ & $\begin{array}{l}\text { AY, Epi. } \\
\text { Removal }\end{array}$ & IY & & $\begin{array}{c}\text { Residual } \\
\text { Epi. }\end{array}$ \\
\hline 1 & 10 & $98 \%$ & $81 \%$ & $40 \%$ & $99 \%$ & $1.0 \%$ \\
\hline 2 & 20 & $90 \%$ & $83 \%$ & $66 \%$ & $96 \%$ & $0.0 \%$ \\
\hline 3 & 40 & $92 \%$ & $87 \%$ & $76 \%$ & $95 \%$ & $0.2 \%$ \\
\hline
\end{tabular}

Optical activity of the epoxide samples was confirmed through derivatization with 4-nitro-2-bromo-imidazole. The samples synthesized from optically active epichlorohydrin were compared against those of racemic epichlorohydrin. The SFC traces indicated an enantiomeric ratio of 97:3, ${ }^{10}$ which was consistent with the high optical activity observed from the specific rotation.

In conclusion, we have developed an efficient method to prepare enantiopure $(S)$-glycidyl pivalate from $(R)$ epichlorohydrin and pivalic acid. We believe this work provides an alternative to the synthesis of this important building block from readily available and inexpensive materials.

\section{Acknowledgement}

We thank the Bill and Melinda Gates Foundation for theirlongstanding support of our research. In addition, we express gratitude to Greg Reid, Vassil Elitzin, Trevor Laird and John Dillon for their thoughtful commentary and discussion throughout this work. We also thank Silpa Sundaram and Dr. Susan Hershenson for fostering an ecosystem where rapid decisions on project direction can be made.

\section{References and Notes}

1. a) Stover, C.K.; Warrener, P.; VanDevanter, D.R.; Sherman, D.R.; Arain, T.M.; Langhorne, M.H.; Anderson, S.W.; Towell, J.A.; Yuan, Y.; McMurray, D.N.; Kreiswirth, B.N.; Barry, C.E.; Baker, W.R. Nature, 2000, 405, 962-966. b) Conradie, F.; Diacon,
A.H.; Ngubane, N.; Howell, P.; Everitt, D.; Crook, A.M.; Mendel, C.M.; Egizi, E.; Moreira, J.; Timm, J.; McHugh, T.D.; Wills, G.H.; Bateson, A.; Hunt, R.; Niekerk, C.V.; Li, M.; Olugbosi, M.; Spigelman, M. $N$. Engl. J. Med., 2020, 382, 893-902.

2. Orita, A.; Miwa, K.; Uehara, G.; Otera, J. Adv. Synth. Catal., 2007, 349, 2136-2144. b) Thompson, A.M.; Blaser, A.; Anderson, R.F.; Shinde, S.S.; Franzblau, S.G.; Ma, Z.; Denny, W.A.; Palmer, B.D. J. Med. Chem., 2009, 52, 637-645. c) Marsini, M.A.; Reider, P.J.; Sorensen, E.J. J. Org. Chem., 2010, 75, 74797482. d) Thompson, A.M.; Sutherland, H.S.; Palmer, B.D.; Kmentova, I.; Blaser, A.; Franzblau, S.G.; Wan, B.; Wang, Y.; Ma, Z.; Denny, W.A. J. Med. Chem., 2011, 54, 6563-6585. e) Thompson, A.M.; Bonnet, M.; Lee, H.H.; Franzblau, S.G.; Wan, B.; Wong, G.S.; Cooper, C.B.; Denny, W.A. ACS Med. Chem. Lett., 2017, 8, 1275-1280. f) Chen, G.; Zhu, M.; Chen, Y.; Miao, W.; Guo, M.; Jiang, N.; Zhai, X. Chemical Papers, 2020, 74, 3937-3945. g) Strassfeld, D.A.; Wickens, Z.K.; Picazo, E.; Jacobsen, E.N. J. Am. Chem. Soc., 2020, 142, 9175-9180.

3. Private correspondence.

4. Market costs and volumes taken from Indian import/export records.

5. a) Phyllis, E. US2537981, 1951. b) Mueller, A.C. US2772296, 1956. c) June, R.K.; Rapean, J.C. US3075999, 1963. d) Kloos, N.; Drost, J.J.J. US3178454, 1965. e) Smith, D.R. US3335156, 1967. f) Hosokawa, H.; Shikatsu, M.; Fujimoto, T. US5380884, 1995. g) Rosenbrand, G.G.; Stichter, H.; Heymans, D.M.C. US6433217, 2002. h) Gouman, J.; van der Lee, S.R.; van't Sand, R. US8802872, 2014; i) Yaegashi, K.; Furukawa, Y. US6946566, 2005. j) Jiang, C.; Ye, C.; Wang, X.; Yu, Y. k) CN101723920, 2010. Benshun, C. CN104829584, 2015.

6. Chenyu, C.; Changming, C.; Chaoming, H.; Yi, L.; Yang, L.; Ling, W.; Ying, X.; Lin, Z. WO2012037861, 2012.

7. Leuschner, J.; Schäfer, H.; Leuschner, F. Eur. J. Med. Chem., 1994, 29, 241-243.

8. Sung, J.U.; Seong, S.Y.; Kim, Y.S.; Park, J.H. US20200299247, 2020.

9. Brachman, A. E.; Fang, J. C. J. Org. Chem. 1959, 24, 1369- 1371.

10. See Supporting Information for details. 